\title{
Marine Rare Actinobacteria: Isolation, Characterization, and Strategies for Harnessing Bioactive Compounds
}

\author{
Dipesh Dhakal ${ }^{1}$, Anaya Raj Pokhrel ${ }^{1}$, Biplav Shrestha ${ }^{1}$ and Jae Kyung Sohng ${ }^{1,2 *}$ \\ ${ }^{1}$ Department of Life Science and Biochemical Engineering, Sun Moon University, Asan-si, South Korea, ${ }^{2}$ Department of \\ BT-Convergent Pharmaceutical Engineering, Sun Moon University Asan-si, South Korea
}

Actinobacteria are prolific producers of thousands of biologically active natural compounds with diverse activities. More than half of these bioactive compounds have been isolated from members belonging to actinobacteria. Recently, rare actinobacteria existing at different environmental settings such as high altitudes, volcanic areas, and

OPEN ACCESS

Edited by:

Jem Stach,

Newcastle University, United Kingdom

Reviewed by:

Polpass Arul Jose,

Central Salt and Marine Chemicals Research Institute (CSIR), India

Vijay Kumar,

Doon (P.G) College of Agriculture

Science and Technology, India

D. Ipek Kurtboke,

University of the Sunshine Coast,

Australia

*Correspondence:

Jae Kyung Sohng

sohng@sunmoon.ac.kr

Specialty section:

This article was submitted to

Antimicrobials, Resistance and

Chemotherapy

a section of the journal

Frontiers in Microbiology

Received: 30 December 2016

Accepted: 31 May 2017

Published: 15 June 2017

Citation:

Dhakal D, Pokhrel AR, Shrestha B and

Sohng JK (2017) Marine Rare

Actinobacteria: Isolation,

Characterization, and Strategies for

Harnessing Bioactive Compounds.

Front. Microbiol. 8:1106.

doi: 10.3389/fmicb.2017.01106 marine environment have attracted attention. It has been speculated that physiological or biochemical pressures under such harsh environmental conditions can lead to the production of diversified natural compounds. Hence, marine environment has been focused for the discovery of novel natural products with biological potency. Many novel and promising bioactive compounds with versatile medicinal, industrial, or agricultural uses have been isolated and characterized. The natural compounds cannot be directly used as drug or other purposes, so they are structurally modified and diversified to ameliorate their biological or chemical properties. Versatile synthetic biological tools, metabolic engineering techniques, and chemical synthesis platform can be used to assist such structural modification. This review summarizes the latest studies on marine rare actinobacteria and their natural products with focus on recent approaches for structural and functional diversification of such microbial chemicals for attaining better applications.

Keywords: marine rare actinobacteria, bacterial characterization, bioactive compounds, metagenomics, host engineering

\section{INTRODUCTION}

Actinobacteria are Gram-positive bacteria with high GC contents in DNA. They have characteristics presence of intracellular proteasomes, and spores if present are exospores (Cavalier-Smith, 2002). The order Actinomycetales under phylum Actinobacteria includes major producer strains of diverse bioactive compounds. Actinomycetales includes 11 suborders viz. Actinomycineae, Actinopolysporineae, Catenulisporineae, Corynebacterineae, Glycomycineae, Jiangellineae, Micromonosporineae, Propionibacterineae, Pseudonocardineae, Streptomycineae, and Streptosporangineae (http://www.bacterio.net/-classifphyla.html). The genus Streptomyces under sub-order Streptomycineae have been characterized as most important producer of bioactive microbial metabolites (Berdy, 2005). Recently, previously underexplored genera are reported as important resources of diverse bioactive metabolites (Tiwari and Gupta, 2013). These so called rare-actinobacteria are commonly categorized as strains other than Streptomyces (Berdy, 2005) or actinobacteria strains with less frequency of isolation under normal parameters (Lazzarini et al., 2001; Baltz, 2006). 
The un-explored and under-explored habitats including marine ecosystems are believed to be rich sources of such rare actinobacteria, with tremendous potential to produce interestingly new compounds (Hong et al., 2009). These marine actinobacteria with potential of producing bioactive compounds have attracted major attention to search for unique compounds with pharmaceutical and biotechnological applications (Bull and Stach, 2007; Subramani and Aalbersberg, 2013; Azman et al., 2015). Recently, there are reports on the discovery of rare actinobacteria from wide range of terrestrial and aquatic locations, including deep seas (Goodfellow et al., 2012). Reports on the analysis of geographical origins of the marine rare actinobacteria, with special focus on the isolation of specific compounds, and precise bioactivities are predominant indications of increasing global interest on the natural compounds from marine rare actinobacteria (Blunt et al., 2007).

\section{ISOLATION AND CHARACTERIZATION OF MARINE RARE ACTINOBACTERIA}

Generally, for uncovering the marine rare actinobacteria, isolation efforts have been focused on rare locations as deep-sea sediments to obtain new marine diversities (Fenical and Jensen, 2006). The specialized sampling techniques using sophisticated equipment (Fenical and Jensen, 2006), remotely operated vehicles (Pathom-Aree et al., 2006) and even human (Bredholdt et al., 2007), have provided easy access to unprecedented microbial diversity. However, marine rare actinobacteria are usually difficult to culture compared to their terrestrial counterparts mostly due to their special growth requirements (Zotchev, 2012) or unknown culture conditions. It has been observed that hardly $<2 \%$ of bacterial cells can form colonies by conventional plate cultivation. A large number of them belong to "viable but not culturable" (VBNC) strains (Bernard et al., 2000). Recently, strategies such as mimicking the natural environment in terms of $\mathrm{pH}$, oxygen gradient, nutrient compositions, etc is employed. With these improvements, some previously VBNC species can now be grown with more efficiency (Kaeberlein et al., 2002; Zengler et al., 2002; Vartoukian et al., 2010; Stewart, 2012).

Moreover, the laborious microscopic techniques are being replaced with techniques utilizing recent advances in genomics, proteomics, and bioinformatics for identification and characterization of microbial diversity in robust manner (Rastogi and Sani, 2011). The genomic analysis by genetic fingerprinting (Nübel et al., 1999), DNA-DNA hybridization techniques (Pinhassi et al., 1997), and the construction of metagenomic library and sequencing (Kisand et al., 2012) have been employed for identifying and characterizing the diversity within marine samples. The development of next generation sequencing (NGS) (Webster et al., 2010) and nanopore sequencing (Deamer et al., 2016) has made the process robust and less time consuming. The analysis of RNA expression and regulation using metatranscriptomics (Ogura et al., 2011) or determination of protein profile by metaproteomics (Slattery et al., 2012) can be directly linked to available genome in the database. The coupled metagenomics and metatranscriptomic analysis was successfully used for determining the microbial communities in deep sea water of the North Pacific Ocean (Wu J. et al., 2013). Thus, the combination of both culture dependent (grow and isolate) and culture independent (analysis of nucleic acids and proteins) approaches have revolutionized the characterization and isolation of diverse marine organisms including rare actinobacteria (Hirayama et al., 2007; Zeng et al., 2012).

\section{DISCOVERY OF BIOACTIVE COMPOUNDS FROM MARINE RARE ACTINOBACTERIA}

Actinobacteria including Streptomyces contribute for approximately half of the characterized bioactive compounds up to date (Berdy, 2005). However, the chances of discovery of novel bioactive molecules from Streptomyces has significantly declined (Fenical et al., 1999), presumably due to easy chances of genetic exchange between species during evolution (Freel et al., 2011). Therefore, special attention is given to isolation, screening, and culturing of rare actinobacteria from rare environmental locations as marine sources. The list below summarizes some of the representative compounds isolated from diverse marine rare actinobacteria during last 10 years (Table 1A).

\section{REINVIGORATING NATURAL PRODUCT DISCOVERY FROM MARINE RARE ACTINOBACTERIA}

Though isolation and cultivation of marine rare actinobacteria is difficult, the development of novel and facile bacterial cultivation platforms such as hollow-fiber membrane chamber (HFMC) and iChip for in situ cultivation of previously unculturable microbial species have expanded the scope of natural product discovery (Aoi et al., 2009; Nichols et al., 2010). By utilizing rationally designed iChip platform, Ling et al. (2015) has successfully isolated previously uncultivable soil bacteria Eleftheria terrae and characterized its bioactive molecule (Ling et al., 2015).

It is assumed that strain divergence (phylogenetic or ecological) can have great impact on metabolism and biosynthetic pathway and result in novel chemistry and bioactivities, so research is focused on previously unexplored strains (Monciardini et al., 2014). However, it is unrealistic to assume that every unexplored strain can provide bioactive compounds (Donadio et al., 2010). Hence, systematic approaches need to be employed for utilizing the true potential of natural products from marine rare actinobacteria. Some of the key foundations can be categorized as:

1. Identification of target strains/molecules,

2. Systematic enrichment of production,

3. Explicit modification for functional/structural diversity.

1. Identification of target strains/molecules

The accessible diversity of useful microbial molecules have almost been exhausted by traditional approaches, hence 
TABLE 1 | Overview of achievements in study of bioactive molecules derived from marine rare actinobacteria.

\section{A. Examples of bioactive compounds isolated from various marine rare actinobacteria}

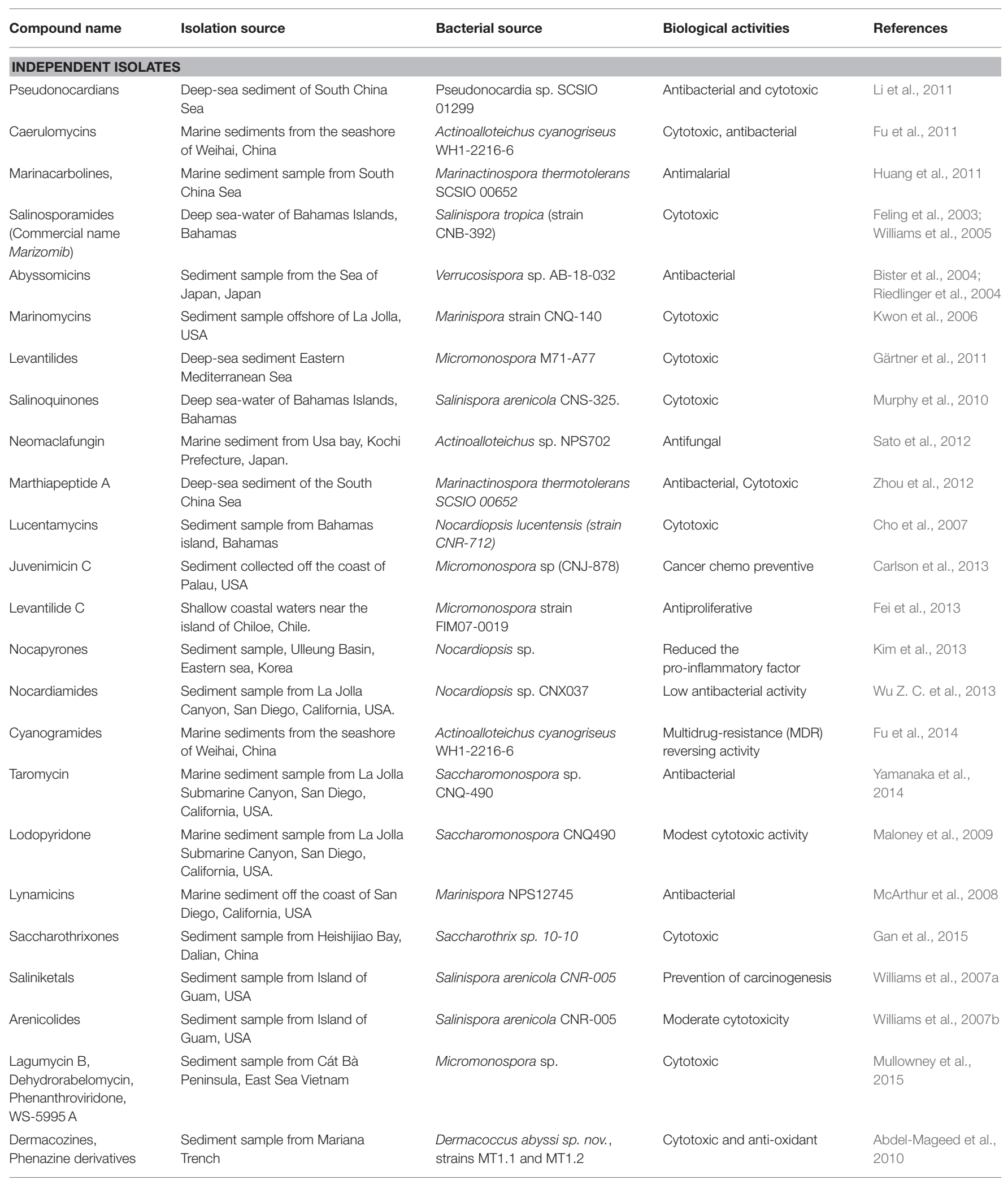


TABLE 1 | Continued

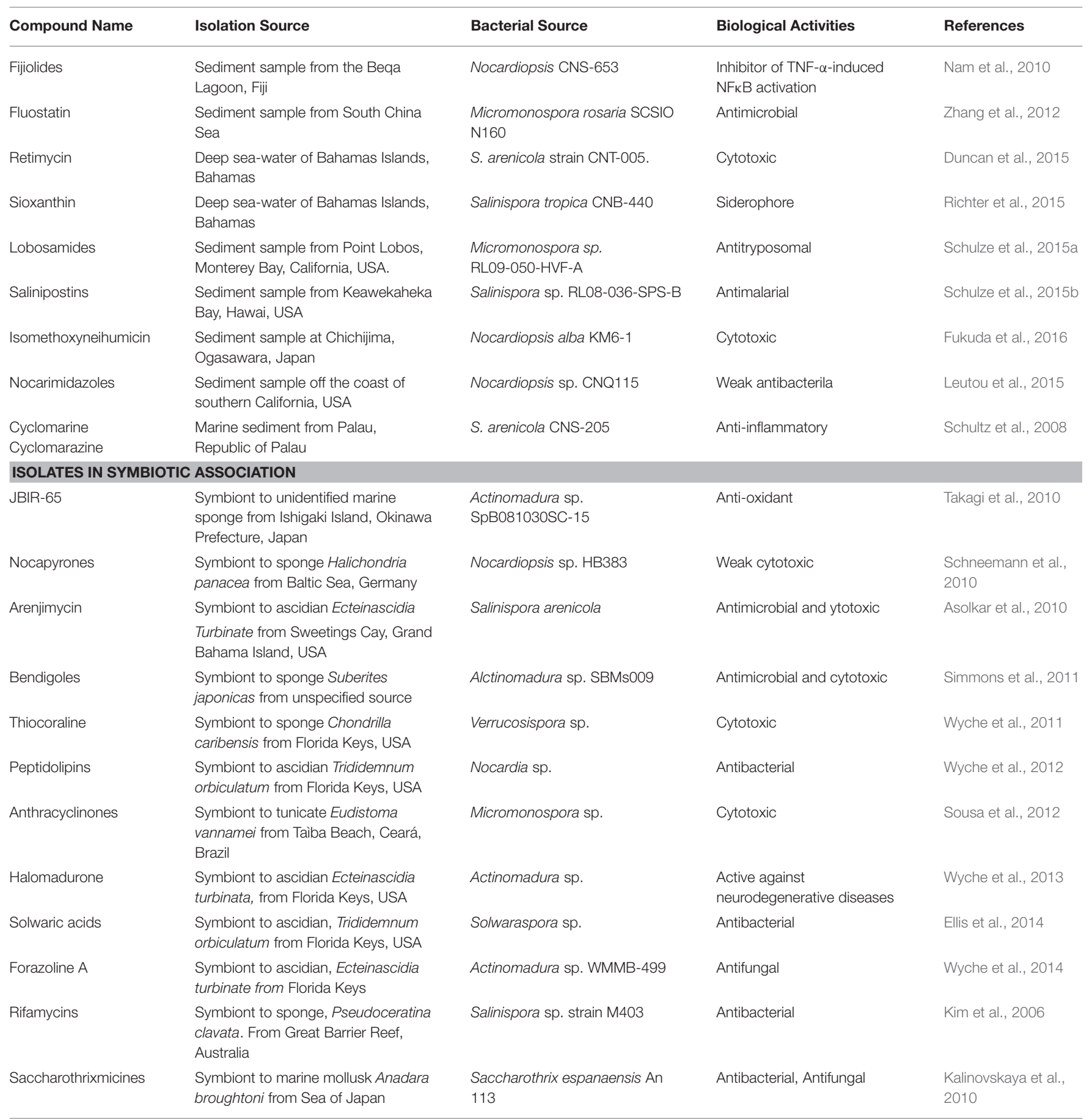

B. Approaches used for production and structural/functional diversification of bioactive compounds derived from marine rare actinobacteria

\begin{tabular}{llll}
\hline Compound name & Genus & Particulars & Biological activity \\
\hline Retimycin & Salinospora & $\begin{array}{l}\text { MS/MS spectrum pattern based } \\
\text { genome mining }\end{array}$ & Cytotoxic, Antibacterial \\
Thiolactomycin & Salinospora & $\begin{array}{l}\text { Antibiotic resistance gene based } \\
\text { genome mining, heterologous } \\
\text { expression }\end{array}$ & $\begin{array}{l}\text { Bacterial fatty acid synthase } \\
\text { inhibitor }\end{array}$ \\
& & Tang et al., 2015
\end{tabular}


TABLE 1 | Continued

\begin{tabular}{|c|c|c|c|c|}
\hline Compound name & Genus & Particulars & Biological activity & References \\
\hline Lomaiviticin & Salinospora & Bioactivity guided genome mining & Cytotoxic & Kersten et al., 2013 \\
\hline Salinosporamide K & Salinospora & $\begin{array}{l}\text { Genome mining, metabolomics and } \\
\text { transcriptomics }\end{array}$ & Cytotoxic & Eustáquio et al., 2011 \\
\hline Taromycin & Saccharomonospora & $\begin{array}{l}\text { BCG Genome mining, heterologous } \\
\text { expression }\end{array}$ & Antibacterial & Yamanaka et al., 2014 \\
\hline Enterocin & Salinispora & $\begin{array}{l}\text { BCG Genome mining, heterologous } \\
\text { expression }\end{array}$ & Antibacterial & Bonet et al., 2014 \\
\hline Fluostatins & Micromonospora & Heterologous expression & Antibacterial & Yang et al., 2015 \\
\hline Thiocoraline & Micromonospora & Heterologous expression & Cytotoxic & Lombó et al., 2006 \\
\hline Bromosalinosporamide & Salinospora & Precursor directed biosynthesis & Cytotoxic & Lam et al., 2007 \\
\hline Salinosporamide A & Salinospora & Precursor pathway modulation & Cytotoxic & Lechner et al., 2011 \\
\hline $\begin{array}{l}\text { Salinosporamide X1, } \\
\text { Salinosporamide X2 }\end{array}$ & Salinospora & Combinatorial biosynthesis & Cytotoxic & McGlinchey et al., 2008 \\
\hline \multicolumn{5}{|l|}{ Salinosporamide X6 } \\
\hline \multicolumn{5}{|l|}{ Salinosporamide $X 7$} \\
\hline Fluorosalinosporamide & Salinospora & Mutasynthesis & Cytotoxic & Eustáquio and Moore, 2008 \\
\hline Salinosporamides analogs & Salinospora & Chemobiosynthesis & Cytotoxic & Liu et al., 2009 \\
\hline Salinosporamide A & Salinospora & Total chemical synthesis & Cytotoxic & $\begin{array}{l}\text { Reddy et al., 2004; Endo and } \\
\text { Danishefsky, 2005; Kaiya et al., } \\
\text { 2011; Logan et al., } 2014\end{array}$ \\
\hline Homosalinosporamide & Salinospora & Total chemical synthesis & Cytotoxic & Nguyen et al., 2010 \\
\hline Salinosporamides analogs & Salinospora & Chemobiosynthesis & Cytotoxic & Liu et al., 2009 \\
\hline Salinosporamide E & Salinospora & Semi-synthesis & Cytotoxic & Macherla et al., 2005 \\
\hline \multicolumn{5}{|l|}{ Bromosalinospramide } \\
\hline Flurosalinosporamide & & & & \\
\hline
\end{tabular}

it is speculated that unstudied marine rare actinobacteria can provide reservoir of new microbial molecules (Schorn et al., 2016). Recently, direct connection of genomic information to biomolecule can be attained in culture independent approach as introducing environment (eDNA) into a suitable expression host (metagenomic libraries) (Handelsman, 2004). But, compound rediscovery due to similar strain replications is a major limitation of this approach. To maximize the capacity to mine metagenomes for attaining biomolecules with novel activities, there is requisite for parallel developments in techniques for bioactivity screening, isolation and separation methods, and analytical chemistry (Trindade et al., 2015). Robust techniques for analytical characterization of compounds (Figure 1A) based on UV absorbance, high pressure liquid chromatography (HPLC), mass spectrometry, and nuclear magnetic resonance (NMR) analysis can be used to scrutinize the discovery of new compounds (Liu et al., 2012). The techniques utilizing coupling of biochemical analytical methods with genome information such as, in glycogenomics (Kersten et al., 2013), peptidogenomics (Medema et al., 2014), and metabolomics (Maansson et al., 2016) are recent advances facilitating easy access to diverse biomolecules. The results of such analytical analysis can be subsequently compared against databases repositories, such as MarinLit, ChemSpider, Pubchem, etc., to avoid already known compounds (Forner et al., 2013). Hence, robust analytical facilities and comparison with reference databases can assist on characterization of diverse chemical structures.

The prime focus in drug discovery is identification of new bioactive chemical or discovery of previously unreported biological activity with known chemical structure. High throughput screening (HTS) can provide easy means for evaluating desired bioactivities against an array natural 


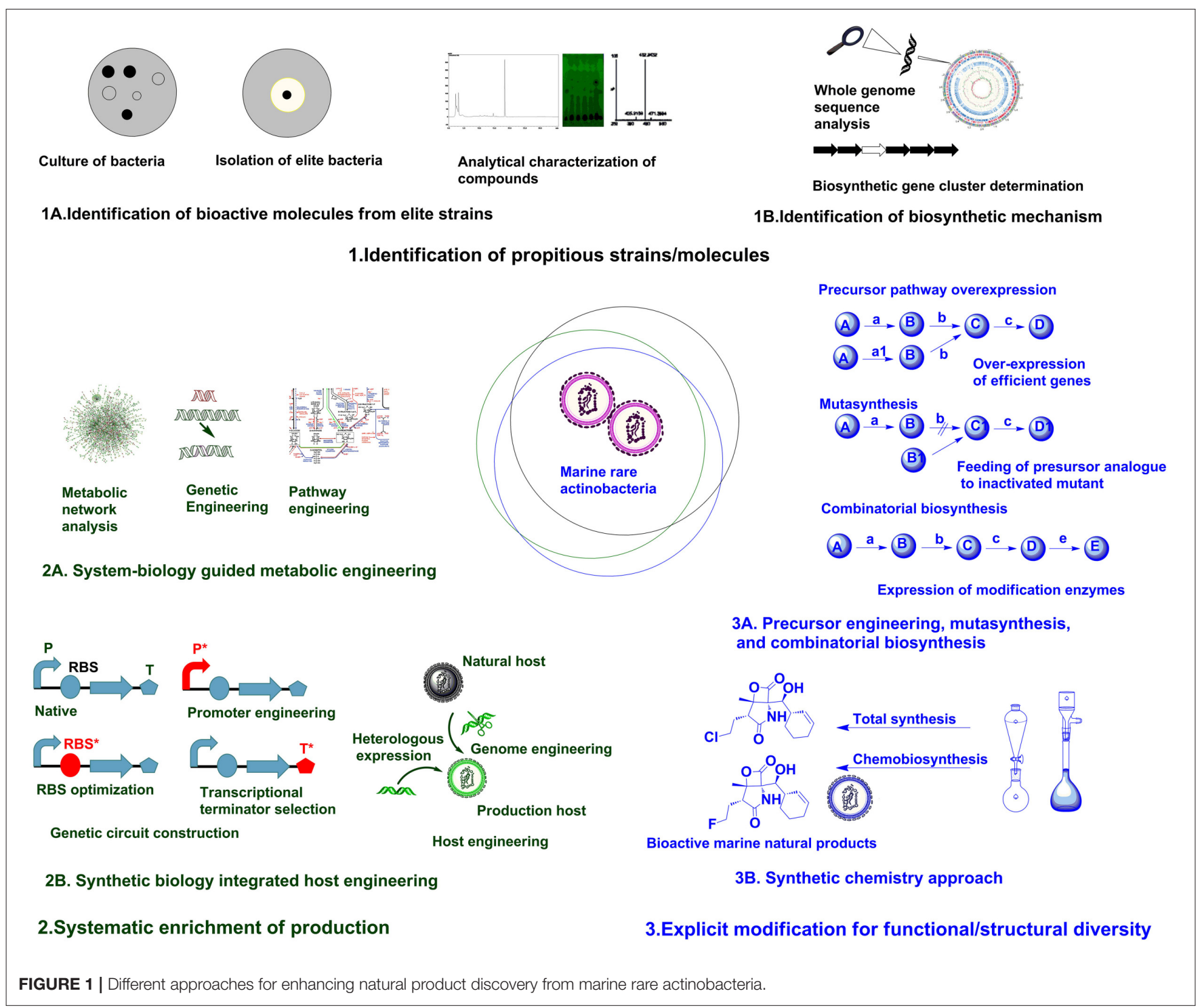

products (Monciardini et al., 2014). The robust screening strategies ranging from the classic whole cell assays to more sophisticated antisense based assay have been reviewed elsewhere (Silver and Bostian, 1990; Singh et al., 2011; Farha and Brown, 2016). Recently, the integrative approach of metabolite profiling, bioactivity studies and taxonomic studies have been utilized for characterizing different marine actinobacteria and biological properties of metabolites produced by them (Betancur et al., 2017). Such integrative approaches can be fascinating tool for directly assessing bioactivities at preliminary stages of study.

The next focus in drug discovery is understanding the biogenesis of bioactive molecule in producer strains. The rapid development of genome sequencing methods has revolutionized such studies by unveiling information about the whole genome architecture (Figure 1B). The challenge now is mining the data and connect the predicted biosynthetic gene clusters (BGC) to bioactive molecules. A plethora of in silico tools are available for determining the nature of gene clusters (Weber and Kim, 2016). The classic genome mining approach (focusing on unique biosynthetic enzyme) has transitioned to the concept of comparative genome mining (complete BGC to next BGC comparison) and culture independent-metagenome mining (Ziemert et al., 2016). Due to its efficacy in studying BGCs, the genome mining concept has been expanded to different marine rare actinobacteria for getting insight on biosynthesis mechanisms of different secondary metabolites. The analysis of genome sequence of Micromonospora sp. RV43, Rubrobacter sp. RV113, and Nocardiopsis sp. RV163 isolated from Mediterranean sponges revealed presence of numerous gene clusters of different secondary metabolites (Horn et al., 2015). The $5.2 \mathrm{Mb}$ genome of marine rare actinobacteria, Salinispora tropica CNB-440 (Udwary et al., 
2007) was interpreted using bioinformatics revealing at least 19 novel secondary metabolite BCGs. Later, diverse compounds have been characterized from S. tropica, including anticancer agent salinosporamide A, lymphocyte kinase inhibitor lymphostin, DNA-cleaving agent calicheamicin, novel lysin-primed polyene macrolactam polyketide, and various siderophores (Kersten et al., 2013). Biosynthetic analysis of the draft genome of Saccharomonospora sp. CNQ490 has revealed 19 conspicuous BGC, indicating diverse secondary metabolic capacity (Yamanaka et al., 2014). Using precise bioinformatics tools, 75 genomes from closely related Salinospora species were compared and 124 distinct prominent BCGs were predicted which are far greater than known compound classes from these bacteria (Ziemert et al., 2014). Duncan et al. (2015) has simultaneously compared a large number of complex microbial extract in a large number of Salinispora species. This molecular networking was coupled with genome sequence data for comparative analysis of metabolite profile and BCG to develop patternbased genome mining (PBGM) approach. Concurrently, a novel non-ribosomal peptide, retimycin A was isolated and characterized based on genome and metabolome analysis (Duncan et al., 2015). Therefore, genome mining approach has provided new avenues on discoursing novel natural products from marine rare actinobacteria.

2. Systematic enrichment of production

Generally, genome information is the starting point for pathway discovery. Various "omics" based tools have been employed for engineering pathways for secondary metabolite production in various actinobacteria (Chaudhary et al., 2013; Hwang et al., 2014). But the lack of full understanding of physiological transition stage for secondary metabolite production is a major consideration during manipulation of cellular processes using metabolic engineering (LiconaCassani et al., 2015). Engineering primary metabolism for enhancing the pools of building blocks without compromising the growth is a major constraint in most metabolic engineering approaches (Olano et al., 2008). System biology protocols have been successfully used to study physiological parameters, leading to the discovery of the activation of NPs biosynthesis and manipulation of pathways (LiconaCassani et al., 2015). Genome scale metabolic models are valuable for predicting organisms' phenotypes from genotypes basically by providing simulated mathematical prediction of cellular behavior under different genetic and physiological conditions (Henry et al., 2010; Ates et al., 2011). Community system biology approaches provide understanding about the complex relationship of individual members in a community and the modes of interactions they are engaged (Zengler and Palsson, 2012). The systematic application of systems biological approaches as metabolic network analysis coupled with pathway engineering or genetic engineering (Figure 2A) from a single strain to the larger community level can provide breakthrough in rational metabolic engineering approaches.

Synthetic biology is particularly focused on precise design and construction of new biological systems (metabolic pathways or genetic circuits) that are not prevalent in nature (Andrianantoandro et al., 2006). Previously, efforts in synthetic biology have been largely focused on creating and perfecting genetic devices. But the current focus is directed to customizable larger scale system engineering by assembling devices or modular organizations (Purnick and Weiss, 2009). Most often, biologically valuable natural products are produced in lower titer or are cryptic under normal laboratory conditions, whereas many rare actinobacteria are not amenable to genetic manipulation. Hence, in such cases transferring natural products biosynthesis into well-developed heterologous host is a logical approach for producing parent NPs or generating novel analogs through biosynthetic engineering (Wenzel and Müller, 2005). Direct cloning and refactoring of previously silent lipopeptide gene cluster of Saccharomonospora sp. CNQ490 have been achieved by heterologous expression in Streptomyces coelicolor to yield taromycin A by Transformation Assisted Recombination (TAR)-based genetic platform (Yamanaka et al., 2014). Besides, tuning of metabolic pathway by altering promoters (Siegl et al., 2013; Wang et al., 2013), terminators (Pulido and Jimenez, 1987), and RBS (Bai et al., 2015) and/or host manipulation by genome engineering (Siegl and Luzhetskyy, 2012; Tong et al., 2015) are providing new avenues for systemic level metabolic engineering of actinobacteria. Promoter exchange (Horbal et al., 2012) and the use of exogenous principal sigma factor $(\sigma \mathrm{HrdB})$ (Wang et al., 2014) have been utilized for increasing teicoplanin in an industrial strain of Actinoplanes teichomyceticus. Approach for constructing genetic circuit or holistic host engineering (Figure 2B) can be an effective approach for designing and synthesizing unnatural but effective molecules from marine rare actinobacteria.

3. Explicit modification for functional/structural diversity

Fundamentally, engineering or modulating the precursor pathways can lead to enhancement or diversification of natural products (Dhakal et al., 2016). Combinatorial biosynthesis exploits the shuffling of anabolic pathways by precursor directed biosynthesis, enzyme level modulations, and pathway level recombination, leading to novel natural products (Sun et al., 2015; Winn et al., 2016). The precursor-directed in-situ synthesis (PDSS) has been successfully employed for generating new congeners of saccharothriolides from Saccharothrix sp. A1506 (Lu et al., 2016). Such type of precursor modulations can be manifested chemically or biologically to generate structural diversity in compounds from marine rare actinobacteria. Mutasynthesis is another variant of modulation of anabolic pathway by generating mutant strain deficient in key aspects of biosynthetic pathway and substituting natural precursor with analog of precursor to produce new natural products (Kennedy, 2008). Mutasynthesis couples the power of chemical synthesis with molecular biology to create diverse derivatives of medicinally valuable natural products (Weissman, 2007). One such example is the production of fluorinated analog fluorosalinosporamide. It has better proteasome inhibition and cytotoxic activity than naturally produced salinosporamides isolated from various Salinispora species (Feling et al., 2003). The halogenase gene salL in Salinispora tropica has been inactivated and 
$5^{\prime}$-fluoro- $5^{\prime}$-deoxyadenosine, a fluorinated analog of its natural precursor $5^{\prime}$-chloro- $5^{\prime}$-deoxyadenosine, has been used to generate fluorosalinosporamide by chemistry mediated mutasynthesis (Eustáquio and Moore, 2008). In another approach, salL was replaced by fluorinase gene $f l A$ from Streptomyces catteleya. The mutant strain $\mathrm{salL}^{-} \mathrm{flA}+$ produced fluorosalinosporamide in the presence of inorganic fluoride (Eustáquio et al., 2010). Moreover, combinatorial biosynthetic approach by feeding L-3-cyclohex-2'-enylalanine (CHA) residue in SalX disruption mutant of $S$. tropica enabled the generation of other unnatural salinosporamide derivatives such as salinosporamide $\mathrm{X} 1$ and salinosporamide $\mathrm{X} 2$, with lower activity (McGlinchey et al., 2008). But in another approach utilizing mutasynthetic approach with fine-tuned feeding of readily available amino acid precursors to SalX disruption mutant of $S$. tropica led to generation of many salinosporamide derivatives. Among them salinosporamide X7 exhibited equal to slightly improved cytotoxic potential than the natural counterpart (Nett et al., 2009). Hence, such approaches of precursor engineering, mutasynthesis, and combinatorial biosynthesis (Figure 3A, Table 1B) can be rationally utilized to diversify structure and perform structure-activity relationship studies of versatile molecules from various marine rare actinobacteria.

The advent of combinatorial synthetic chemistry has created huge excitement in the pharmaceutical industry by generating libraries of millions of compounds which could be screened by HTS (Butler, 2004). The total synthesis of complex natural products offers greater potential for direct access to bioactive molecule from marine sources. However, large scale production of complex natural product remains elusive due to low yields and high cost (Yeung and Paterson, 2005). Recent achievement as total synthesis of natural products in absence of protecting groups can lead to development of superior molecules with greater flexibility (Young and Baran, 2009). The generation of microbial chemicals by total enzymatic synthesis has been used as alternative to total chemical synthesis (Cheng et al., 2007). There have been ample of examples illustrating improvement in physical and biological properties of natural products (including many marine natural products) by chemical modifications, semisynthesis, mutasynthesis, and chemobiosynthesis (Hamann, 2003; Kennedy, 2008) mediated by biological and chemical techniques. Bioinspired total synthesis of salinosporamides and structurally related derivatives have provided access to novel functionalities of tremendously effective molecule (Nguyen et al., 2010; Chen et al., 2012). Suitable integration of synthetic chemistry (Figure 3B, Table 1B) with biological production system can be utilized for generating structurally and functionally diverse analogs/derivatives of target molecule. One of the successful example illustrating application of synthetic chemistry in marine natural products is rationalized for structural/functional diversification of salinosporamides (Baran et al., 2007; Potts and Lam, 2010). The synergy between genome sequencing, mass spectroscopy based analysis and bio-inspired synthesis have been utilized for studying biosynthetic mechanism and structural diversification of nocardioazine $\mathrm{B}$ from Nocardiopsis sp. CMB-M0232 (Alqahtani et al., 2015). Hence, it is no doubt that rational integration of biological processes and chemical techniques (Dhakal and Sohng, 2015, 2017) can provide new foundations for drug discoveries from marine rare actinobacteria.

\section{FUTURE OUTLOOK}

As evident from examples above, the innovative methods for procurement of bioactive molecules from potent strains, efficient production and/or modifications by biological and chemical methods can assist in harnessing the full potential of biomolecules derived from marine rare actinobacteria. Further, tuning of structural and functional properties based on structure activity relationship studies can lead to development of superior analogs. But the prime focus should be on application of cutting edge translational research, such as transferring the achievements of discovery or synthesis of such biomolecule to the industrial bench-tops and clinics. The successful collaboration between biologists/chemists in academics and/or pharmaceutical companies can open new avenues for development of highly effective drugs. Salinosporamide A (Marizomib) has been a significant representation of compound derived from marine rare actinobacteria leading to phase trials. It is no doubt that exploration of new candidate strains with sophisticated techniques will certainly unravel tremendous opportunities to identify novel natural products and improve their applicability by structural/functional diversifications.

\section{AUTHOR CONTRIBUTIONS}

DD, ARP, BS, and JS made substantial, direct, and intellectual contribution to the work, and approved it for publication with full consent.

\section{ACKNOWLEDGMENTS}

This work was supported by the National Research Foundation of Korea (NRF) grant funded by the Korea government (MEST) (NRF-2017R1A2A2A05000939).

\section{REFERENCES}

Abdel-Mageed, W. M., Milne, B. F., Wagner, M., Schumacher, M., Sandor, P., Pathom-aree, W., et al. (2010). Dermacozines, a new phenazine family from

deep-sea dermacocci isolated from a Mariana Trench sediment. Org. Biomol. Chem. 8, 2352-2362. doi: 10.1039/c001445a

Alqahtani, N., Porwal, S. K., James, E. D., Bis, D. M., Karty, J. A., Lane, A. L., et al. (2015). Synergism between genome sequencing, tandem mass spectrometry 
and bio-inspired synthesis reveals insights into nocardioazine B biogenesis. Org. Biomol. Chem. 13, 7177-7192. doi: 10.1039/C5OB00537J

Andrianantoandro, E., Basu, S., Karig, D. K., and Weiss, R. (2006). Synthetic biology: new engineering rules for an emerging discipline. Mol. Syst. Biol. 2:2006.0028. doi: $10.1038 / \mathrm{msb} 4100073$

Aoi, Y., Kinoshita, T., Hata, T., Ohta, H., Obokata, H., and Tsuneda, S. (2009). Hollow-fiber membrane chamber as a device for in situ environmental cultivation. Appl. Environ. Microbiol. 75, 3826-3833. doi: 10.1128/AEM.02542-08

Asolkar, R. N., Kirkland, T. N., Jensen, P. R., and Fenical, W. (2010). Arenimycin, an antibiotic effective against rifampin-and methicillin-resistant Staphylococcus aureus from the marine actinomycete Salinispora arenicola. J. Antibiot. 63, 37-39. doi: 10.1038/ja.2009.114

Ates, Ö., Oner, E. T., and Arga, K. Y. (2011). Genome-scale reconstruction of metabolic network for a halophilic extremophile, Chromohalobacter salexigens DSM 3043. BMC Syst. Biol. 5:12. doi: 10.1186/1752-0509-5-12

Azman, A. S., Othman, I., Velu, S. S., Chan, K. G., and Lee, L. H. (2015). Mangrove rare actinobacteria: taxonomy, natural compound, and discovery of bioactivity. Front. Microbiol. 6:856. doi: 10.3389/fmicb.2015.00856

Bai, C., Zhang, Y., Zhao, X., Hu, Y., Xiang, S., Miao, J., et al. (2015). Exploiting a precise design of universal synthetic modular regulatory elements to unlock the microbial natural products in Streptomyces. Proc. Natl. Acad. Sci. U.S.A.112, 2181-12186. doi: 10.1073/pnas.1511027112

Baltz, R. H. (2006). Marcel Faber Roundtable: is our antibiotic pipeline unproductive because of starvation, constipation or lack of inspiration? J. Ind. Microbiol. Biotechnol. 33, 507-513. doi: 10.1007/s10295-005-0077-9

Baran, P. S., Maimone, T. J., and Richter, J. M. (2007). Total synthesis of marine natural products without using protecting groups. Nature $446,404-408$. doi: 10.1038/nature05569

Berdy, J. (2005). Bioactive microbial metabolites. J. Antibiot. 58, 1-26. doi: $10.1038 /$ ja.2005.1

Bernard, L., Schäfer, H., Joux, F., Courties, C., Muyzer, G., and Lebaron, P. (2000). Genetic diversity of total, active and culturable marine bacteria in coastal seawater. AME 23, 1-11. doi: 10.3354/ame023001

Betancur, L. A., Naranjo-Gaybor, S. J., Vinchira-Villarraga, D. M., MorenoSarmiento, N. C., Maldonado, L. A., Suarez-Moreno, Z. R., et al. (2017). Marine Actinobacteria as a source of compounds for phytopathogen control: an integrative metabolic-profiling/bioactivity and taxonomical approach. PLoS ONE 12:e0170148. doi: 10.1371/journal.pone.0170148

Bister, B., Bischoff, D., Ströbele, M., Riedlinger, J., Reicke, A., Wolter, F., et al. (2004). Abyssomicin C-A polycyclic antibiotic from a marine Verrucosispora Strain as an inhibitor of the p-aminobenzoic acid/tetrahydrofolate biosynthesis pathway. Angew. Chem. Int. Ed. Engl. 43, 2574-2576. doi: 10.1002/anie.200353160

Blunt, J. W., Copp, B. R., Hu, W. P., Munro, M. H., Northcote, P. T., and Prinsep, M. R. (2007). Marine natural products. Nat. Prod. Rep. 24, 31-86. doi: $10.1039 / \mathrm{b} 603047 \mathrm{p}$

Bonet, B., Teufel, R., Cruüsemann, M., Ziemert, N., and Moore, B. S. (2014). Direct capture and heterologous expression of Salinispora natural product genes for the biosynthesis of enterocin. J. Nat. Prod. 78, 539-542. doi: 10.1021/np $500664 \mathrm{q}$

Bredholdt, H., Galatenko, O. A., Engelhardt, K., Fjærvik, E., Terekhova, L. P., and Zotchev, S. B. (2007). Rare actinomycete bacteria from the shallow water sediments of the Trondheim fjord, Norway: isolation, diversity and biological activity. Environ. Microbiol. 9, 2756-2764. doi: 10.1111/j.1462-2920.2007.01387.x

Bull, A. T., and Stach, J. E. (2007). Marine actinobacteria: new opportunities for natural product search and discovery. Trends Microbiol. 15, 491-499. doi: 10.1016/j.tim.2007.10.004

Butler, M. S. (2004). The role of natural product chemistry in drug discovery. J. Nat. Prod. 67, 2141-2153. doi: 10.1021/np040106y

Carlson, S., Marler, L., Nam, S. J., Santarsiero, B. D., Pezzuto, J. M., and Murphy, B. T. (2013). Potential chemopreventive activity of a new macrolide antibiotic from a marine-derived Micromonospora sp. Mar. Drugs. 11, 1152-1161. doi: $10.3390 / \mathrm{md} 11041152$

Cavalier-Smith, T. (2002). The neomuran origin of archaebacteria, the negibacterial root of the universal tree and bacterial megaclassification. Int. J. Syst. Evol. Microbiol. 52, 7-76. doi: 10.1099/00207713-52-1-7
Chaudhary, A. K., Dhakal, D., and Sohng, J. K. (2013). An insight into the "-omics" based engineering of streptomycetes for secondary metabolite overproduction. Biomed. Res. Int. 2013:968518. doi: 10.1155/2013/ 968518

Chen, Z. H., Wang, B. L., Kale, A. J., Moore, B. S., Wang, R. W., and Qing, F. L. (2012). Coupling of sterically hindered aldehyde with fluorinated synthons: stereoselective synthesis of fluorinated analogues of salinosporamide A. J. Fluor. Chem. 136, 12-19. doi: 10.1016/j.jfluchem.2012. 01.003

Cheng, Q., Xiang, L., Izumikawa, M., Meluzzi, D., and Moore, B. S. (2007). Enzymatic total synthesis of enterocin polyketides. Nat. Chem. Biol. 3, 557-558. doi: $10.1038 /$ nchembio.2007.22

Cho, J. Y., Williams, P. G., Kwon, H. C., Jensen, P. R., and Fenical, W. (2007). Lucentamycins, A. D., cytotoxic peptides from the marinederived actinomycete Nocardiopsis lucentensis. J. Nat. Prod. 70, 321-1328. doi: 10.1021/np070101b

Deamer, D., Akeson, M., and Branton, D. (2016). Three decades of nanopore sequencing. Nat. Biotechnol. 34, 518-524. doi: 10.1038/nbt.3423

Dhakal, D., and Sohng, J. K. (2015). Commentary: toward a new focus in antibiotic and drug discovery from the Streptomyces arsenal. Front. Microbiol. 6:727. doi: $10.3389 /$ fmicb.2015.00727

Dhakal, D., and Sohng, J. K. (2017). Coalition of biology and chemistry for ameliorating antimicrobial drug discovery. Front. Microbiol. 8:734. doi: 10.3389/fmicb.2017.00734

Dhakal, D., Chaudhary, A. K., Yi, J. S., Pokhrel, A. R., Shrestha, B., Parajuli, P., et al. (2016). Enhanced production of nargenicin A1 and creation of a novel derivative using a synthetic biology platform. Appl. Microbiol. Biotechnol. 100, 9917-9931. doi: 10.1007/s00253-016-7705-3

Donadio, S., Maffioli, S., Monciardini, P., Sosio, M., and Jabes, D. (2010). Antibiotic discovery in the twenty-first century: current trends and future perspectives. $J$. Antibiot. 63, 423-430. doi: 10.1038/ja.2010.62

Duncan, K. R., Crüsemann, M., Lechner, A., Sarkar, A., Li, J., Ziemert, N., et al. (2015). Molecular networking and pattern-based genome mining improves discovery of biosynthetic gene clusters and their products from Salinispora species. Chem. Biol. 22, 460-471. doi: 10.1016/j.chembiol.2015. 03.010

Ellis, G. A., Wyche, T. P., Fry, C. G., Braun, D. R., and Bugni, T. S. (2014). Solwaric acids A and B, antibacterial aromatic acids from a marine Solwaraspora sp. Mar. Drugs 12, 1013-1022. doi: 10.3390/md12021013

Endo, A., and Danishefsky, S. J. (2005). Total synthesis of salinosporamide A. J. Am. Chem. Soc. 127, 8298-8299. doi: 10.1021/ja0522783

Eustáquio, A. S., and Moore, B. S. (2008). Mutasynthesis of fluorosalinosporamide, a potent and reversible inhibitor of the proteasome. Angew. Chem. Int. Ed. Engl. 47, 3936-3938. doi: 10.1002/anie. 200800177

Eustáquio, A. S., Nam, S. J., Penn, K., Lechner, A., Wilson, M. C., Fenical, W., et al. (2011). The discovery of salinosporamide K from the marine bacterium "Salinispora pacifica" by genome mining gives insight into pathway evolution. Chembiochem 12, 61-64. doi: 10.1002/cbic.2010 00564

Eustáquio, A. S., O’Hagan, D., and Moore, B. S. (2010). Engineering fluorometabolite production: fluorinase expression in Salinispora tropica yields fluorosalinosporamide. J. Nat. Prod. 73, 378-382. doi: 10.1021/np9 $00719 u$

Farha, M. A., and Brown, E. D. (2016). Strategies for target identification of antimicrobial natural products. Nat. Prod. Rep. 33, 668-680. doi: 10.1039/C5NP00127G

Fei, P., Chuan-xi, W., Yang, X., Hong-lei, J., Lu-jie, C., Uribe, P., et al. (2013). A new 20-membered macrolide produced by a marine-derived Micromonospora strain. Nat. Prod. Res. 27, 1366-1371. doi: 10.1080/14786419.2012. 740038

Feling, R. H., Buchanan, G. O., Mincer, T. J., Kauffman, C. A., Jensen, P. R., and Fenical, W. (2003). Salinosporamide A: a highly cytotoxic proteasome inhibitor from a novel microbial source, a marine bacterium of the new genus Salinospora. Angew. Chem. Int. Ed. Engl. 42, 355-357. doi: 10.1002/anie.2003 90115

Fenical, W., and Jensen, P. R. (2006). Developing a new resource for drug discovery: marine actinomycete bacteria. Nat. Chem. Biol. 2, 666-673. doi: $10.1038 /$ nchembio841 
Fenical, W., Baden, D., Burg, M., de-Goyet, C. V., Grimes, J. D., Katz, M., et al. (1999). "Marine derived pharmaceuticals and related bioactive compounds," in From Monsoons to Microbes: Understanding the Ocean's Role in Human Health, ed W. Fenical (Washington, DC: National Academies Press), 71-86.

Forner, D., Berrué, F., Correa, H., Duncan, K., and Kerr, R. G. (2013). Chemical dereplication of marine actinomycetes by liquid chromatography-high resolution mass spectrometry profiling and statistical analysis. Anal. Chim. Acta 805, 70-79. doi: 10.1016/j.aca.2013. 10.029

Freel, K. C., Nam, S. J., Fenical, W., and Jensen, P. R. (2011). Evolution of secondary metabolite gene evolution in three closely related marine actinomycete species. Appl. Environ. Microbiol. 20, 7261-7270. doi: 10.1128/AEM. 05943-11

Fu, P., Kong, F., Li, X., Wang, Y., and Zhu, W. (2014). Cyanogramide with a new spiro [indolinone-pyrroloimidazole] skeleton from Actinoalloteichus cyanogriseus. Org. Lett.16, 3708-3711. doi: 10.1021/ol501523d

Fu, P., Wang, S., Hong, K., Li, X., Liu, P., Wang, Y., et al. (2011). Cytotoxic bipyridines from the marine-derived actinomycete Actinoalloteichus cyanogriseus WH1-2216-6. J. Nat. Prod. 74, 1751-1756. doi: $10.1021 / \mathrm{np} 200258 \mathrm{~h}$

Fukuda, T., Takahashi, M., Nagai, K., Harunari, E., Imada, C., and Tomoda, H. (2016). Isomethoxyneihumicin, a new cytotoxic agent produced by marine Nocardiopsis alba KM6-1. J. Antibiot. 70, 590-594. doi: 10.1038/ja.2016.152

Gan, M., Liu, B., Tan, Y., Wang, Q., Zhou, H., He, H., et al. (2015). Saccharothrixones A-D, tetracenomycin-type polyketides from the marinederived actinomycete Saccharothrix sp. 10-10. J. Nat. Prod. 78, 2260-2265. doi: 10.1021/acs.jnatprod.5b00577

Gärtner, A., Ohlendorf, B., Schulz, D., Zinecker, H., Wiese, J., and Imhoff, J. F. (2011). Levantilides, A., and B, 20-membered macrolides from a Micromonospora strain isolated from the mediterranean deep sea sediment. Mar. Drugs 9, 98-108. doi: 10.3390/md9010098

Goodfellow, M., Stach, J. E., Brown, R., Bonda, A. N. V., Jones, A. L., Mexson, J., et al. (2012). Verrucosispora maris sp. nov., a novel deep-sea actinomycete isolated from a marine sediment which produces abyssomicins. Antonie Van Leeuwenhoek 101, 185-193. doi: 10.1007/s10482-0119651-5

Hamann, M. T. (2003). Enhancing marine natural product structural diversity and bioactivity through semisynthesis and biocatalysis. Curr. Pharm. Des. 9, 879-889. doi: 10.2174/1381612033455297

Handelsman, J. (2004). Metagenomics: application of genomics to uncultured microorganisms. Microbiol. Mol. Biol. Rev. 68, 669-685. doi: 10.1128/MMBR.68.4.669-685.2004

Henry, C. S., DeJongh, M., Best, A. A., Frybarger, P. M., Linsay, B., and Stevens, R. L. (2010). High-throughput generation, optimization and analysis of genomescale metabolic models. Nat. Biotechnol. 28, 977-982. doi: 10.1038/nbt.1672

Hirayama, H., Sunamura, M., Takai, K., Nunoura, T., Noguchi, T., Oida, H., et al. (2007). Culture-dependent and -independent characterization of microbial communities associated with a shallow submarine hydrothermal system occurring within a coral reef off Taketomi Island, Japan. Appl. Environ. Microbiol. 73, 7642-7656. doi: 10.1128/AEM.01258-07

Hong, K., Gao, A. H., Xie, Q. Y., Gao, H. G., Zhuang, L., Lin, H. P., et al. (2009). Actinomycetes for marine drug discovery isolated from mangrove soils and plants in China. Mar. Drugs 7, 24-44. doi: 10.3390/md7010024

Horbal, L., Zaburannyy, N., Ostash, B., Shulga, S., and Fedorenko, V. (2012). Manipulating the regulatory genes for teicoplanin production in Actinoplanes teichomyceticus. World J. Microbiol. Biotechnol. 28, 2095-2100. doi: $10.1007 / \mathrm{s} 11274-012-1013-6$

Horn, H., Hentschel, U., and Abdelmohsen, U. R. (2015). Mining genomes of three marine sponge-associated actinobacterial isolates for secondary metabolism. Genome Announc. 3, e01106-e01115. doi: 10.1128/genomeA. 01106-15

Huang, H., Yao, Y., He, Z., Yang, T., Ma, J., Tian, X., et al. (2011). Antimalarial $\beta$-carboline and indolactam alkaloids from Marinactinospora thermotolerans, a deep sea isolate. J. Nat. Prod. 74, 2122-2127. doi: 10.1021/np200399t

Hwang, K. S., Kim, H. U., Charusanti, P., Palsson, B. Ø., and Lee, S. Y. (2014). Systems biology and biotechnology of Streptomyces species for the production of secondary metabolites. Biotechnol. Adv. 32, 255-268. doi: $10.1016 /$ j.biotechadv.2013.10.008
Kaeberlein, T., Lewis, K., and Epstein, S. S. (2002). Isolating "uncultivable" microorganisms in pure culture in a simulated natural environment. Science 296, 1127-1129. doi: 10.1126/science. 1070633

Kaiya, Y., Hasegawa, J. I., Momose, T., Sato, T., and Chida, N. (2011). Total synthesis of (-)-Salinosporamide, A. Chem. Asian J. 6, 209-219. doi: 10.1002/asia.201000602

Kalinovskaya, N. I., Kalinovsky, A. I., Romanenko, L. A., Dmitrenok, P. S., and Kuznetsova, T. A. (2010). New angucyclines and antimicrobial diketopiperazines from the marine mollusk-derived actinomycete Saccharothrix espanaensis An 113. Nat. Prod. Commun. 5, 597-602.

Kennedy, J. (2008). Mutasynthesis, chemobiosynthesis, and back to semi-synthesis: combining synthetic chemistry and biosynthetic engineering for diversifying natural products. Nat. Prod. Rep. 25, 25-34. doi: 10.1039/B707678A

Kersten, R. D., Ziemert, N., Gonzalez, D. J., Duggan, B. M., Nizet, V., Dorrestein, P. C., et al. (2013). Glycogenomics as a mass spectrometryguided genome-mining method for microbial glycosylated molecules. Proc. Natl. Acad. Sci. U.S.A. 110, E4407-E4416. doi: 10.1073/pnas.13154 92110

Kim, M. C., Kwon, O. W., Park, J. S., Kim, S. Y., and Kwon, H. C. (2013). Nocapyrones H-J, 3, 6-disubstituted $\alpha$-pyrones from the marine actinomycete Nocardiopsis sp. KMF-001. Chem. Pharm. Bull. 61, 511-515. doi: 10.1248/cpb.c12-00956

Kim, T. K., Hewavitharana, A. K., Shaw, P. N., and Fuerst, J. A. (2006) Discovery of a new source of rifamycin antibiotics in marine sponge actinobacteria by phylogenetic prediction. Appl. Environ. Microbiol. 72, 2118-2125. doi: 10.1128/AEM.72.3.2118-2125.2006

Kisand, V., Valente, A., Lahm, A., Tanet, G., and Lettieri, T. (2012). Phylogenetic and functional metagenomic profiling for assessing microbial biodiversity in environmental monitoring. PLoS ONE 7:e43630. doi: 10.1371 /journal.pone. 0043630

Kwon, H. C., Kauffman, C. A., Jensen, P. R., and Fenical, W. (2006), Marinomycins, A-D., antitumor-antibiotics of a new structure class from a marine actinomycete of the recently discovered genus "Marinispora". J. Am. Chem. Soc. 128, 1622-1632. doi: 10.1021/ja0558948

Lam, K. S., Tsueng, G., McArthur, K. A., Mitchell, S. S., Potts, B. C., and $\mathrm{Xu}, \mathrm{J}$. (2007). Effects of halogens on the production of salinosporamides by the obligate marine actinomycete Salinispora tropica. J. Antibiot. 60, 13-19. doi: 10.1038/ja.2007.2

Lazzarini, A., Cavaletti, L., Toppo, G., and Marinelli, F. (2001). Rare genera of actinomycetes as potential producers of new antibiotics. Antonie Van Leeuwenhoek 79, 399-405.

Lechner, A., Eustáquio, A. S., Gulder, T. A., Hafner, M., and Moore, B. S. (2011). Selective overproduction of the proteasome inhibitor salinosporamide A via precursor pathway regulation. Chem. Biol. 18, 1527-1536. doi: 10.1016/j.chembiol.2011.10.014

Leutou, A. S., Yang, I., Kang, H., Seo, E. K., Nam, S. J., and Fenical, W. (2015). Nocarimidazoles, A., and B from a marine-derived actinomycete of the genus Nocardiopsis. J. Nat. Prod. 78, 2846-2849. doi: 10.1021/acs.jnatprod.5b00746

Li, S., Tian, X., Niu, S., Zhang, W., Chen, Y., Zhang, H., et al. (2011). Pseudonocardians A-C, new diazaanthraquinone derivatives from a deapsea actinomycete Pseudonocardia sp. SCSIO 01299. Mar Drugs 9, 1428-1439. doi: $10.3390 / \mathrm{md} 9081428$

Licona-Cassani, C., Cruz-Morales, P., Manteca, A., Barona-Gomez, F., Nielsen, L. K., and Marcellin, E. (2015). Systems biology approaches to understand natural products biosynthesis. Front. Bioeng. Biotechnol. 3:199 doi: 10.3389/fbioe.2015.00199

Ling, L. L., Schneider, T., Peoples, A. J., Spoering, A. L., Engels, I., Conlon, B. P., et al. (2015). A new antibiotic kills pathogens without detectable resistance. Nature 517, 455-459. doi: 10.1038/nature14098

Liu, X., Bolla, K., Ashforth, E. J., Zhuo, Y., Gao, H., Huang, P., et al. (2012). Systematics-guided bioprospecting for bioactive microbial natural products. Antonie Van Leeuwenhoek 101, 55-66. doi: 10.1007/s10482-011-9671-1

Liu, Y., Hazzard, C., Eustáquio, A. S., Reynolds, K. A., and Moore, B. S. (2009). Biosynthesis of salinosporamides from $\alpha, \beta$-unsaturated fatty acids: implications for extending polyketide synthase diversity. J. Am. Chem. Soc. 131, 10376-10377. doi: 10.1021/ja9042824

Logan, A. W., Sprague, S. J., Foster, R. W., Marx, L. B., Garzya, V., Hallside, M. S., et al. (2014). Diastereoselective synthesis of fused lactone-pyrrolidinones; 
application to a formal synthesis of (-)-Salinosporamide, A. Org. Lett. 16, 4078-4081. doi: 10.1021/ol501662t

Lombó, F., Velasco, A., Castro, A., De la Calle, F., and Braña, A. F., SánchezPuelles, J. M., et al. (2006). Deciphering the biosynthesis pathway of the antitumor thiocoraline from a marine actinomycete and its expression in two Streptomyces species. Chembiochem 7, 366-376. doi: 10.1002/cbic.200500325

Lu, S., Nishimura, S., Ito, M., Kato, T., and Kakeya, H. (2016). Precursordirected in situ synthesis of Saccharothriolides, G., and H by the Actinomycete Saccharothrix sp. A1506. J. Antibiot. 70, 718-720. doi: 10.1038/ja.2016.153

Maansson, M., Vynne, N. G., Klitgaard, A., Nybo, J. L., Melchiorsen, J., Nguyen, D. D., et al. (2016). An integrated metabolomic and genomic mining workflow to uncover the biosynthetic potential of bacteria. Msystems 1, e00028-e00015. doi: $10.1128 / \mathrm{mSystems.00028-15}$

Macherla, V. R., Mitchell, S. S., Manam, R. R., Reed, K. A., Chao, T. H., Nicholson, B., et al. (2005). Structure activity relationship studies of salinosporamide A (NPI-0052), a novel marine derived proteasome inhibitor. J. Med. Chem. 48, 3684-3687. doi: 10.1021/jm048995+

Maloney, K. N., MacMillan, J. B., Kauffman, C. A., Jensen, P. R., DiPasquale, A. G., Rheingold, A. L., et al. (2009). Lodopyridone, a structurally unprecedented alkaloid from a marine actinomycete. Org. Lett. 11, 5422-5424. doi: $10.1021 / \mathrm{ol} 901997 \mathrm{k}$

Manam, R. R., McArthur, K. A., Chao, T. H., Weiss, J., Ali, J. A., Palombella, V. J., et al. (2008). Leaving groups prolong the duration of $20 \mathrm{~S}$ proteasome inhibition and enhance the potency of salinosporamides. J. Med. Chem. 51, 6711-6724. doi: $10.1021 / \mathrm{jm} 800548 \mathrm{~b}$

McArthur, K. A., Mitchell, S. S., Tsueng, G., Rheingold, A., White, D. J., Grodberg, J., et al. (2008). Lynamicins A-E, chlorinated bisindole pyrrole antibiotics from a novel marine Actinomycete. J. Nat. Prod. 71, 1732-1737. doi: $10.1021 / \mathrm{np} 800286 \mathrm{~d}$

McGlinchey, R. P., Nett, M., Eustáquio, A. S., Asolkar, R. N., Fenical, W., and Moore, B. S. (2008). Engineered biosynthesis of antiprotealide and other unnatural salinosporamide proteasome inhibitors. J. Am. Chem. Soc. 130:7822. doi: $10.1021 /$ ja 8029398

Medema, M., Paalvast, Y., Nguyen, D., Melnik, A., Dorrestein, P., Takano, E., et al. (2014). Pep2Path: automated mass spectrometry-guided genome mining of peptidic natural products. PLoS Comput. Biol. 10:e1003822. doi: 10.1371/journal.pcbi.1003822

Monciardini, P., Iorio, M., Maffioli, S., Sosio, M., and Donadio, S. (2014). Discovering new bioactive molecules from microbial sources. Microbiol. Biotechnol. 7, 209-220. doi: 10.1111/1751-7915.12123

Mullowney, M. W., Ó hAinmhire, E., Tanouye, U., Burdette, J. E., Pham, V. C., and Murphy, B. T. (2015). A pimarane diterpene and cytotoxic angucyclines from a marine-derived Micromonospora sp. in Vietnam's East Sea. Mar. Drugs. 13, 5815-5827. doi: 10.3390/md13095815

Murphy, B. T., Narender, T., Kauffman, C. A., Woolery, M., Jensen, P. R., and Fenical, W. (2010). Saliniquinones A-F, new members of the highly cytotoxic anthraquinone- $\gamma$-pyrones from the marine actinomycete Salinispora arenicola. Aust. J. Chem. 63, 929-934. doi: 10.1071/CH10068

Nam, S. J., Gaudêncio, S. P., Kauffman, C. A., Jensen, P. R., Kondratyuk, T. P., Marler, L. E., et al. (2010). Fijiolides, A., and B, inhibitors of TNF- $\alpha$-induced $\mathrm{NFKB}$ activation, from a marine-derived sediment bacterium of the genus Nocardiopsis. J. Nat. Prod. 73, 1080-1086. doi: 10.1021/np100087c

Nett, M., Gulder, T. A., Kale, A. J., Hughes, C. C., and Moore, B. S. (2009). Function-oriented biosynthesis of $\beta$-lactone proteasome inhibitors in Salinispora tropica. J. Med. Chem. 52:6163. doi: 10.1021/jm901098m

Nguyen, H., Ma, G., Gladysheva, T., Fremgen, T., and Romo, D. (2010). Bioinspired total synthesis and human proteasome inhibitory activity of (-)salinosporamide A, (-)-homosalinosporamide A, and derivatives obtained via organonucleophile promoted bis-cyclizations. J. Org. Chem. 76, 2-12. doi: 10.1021/jo101638r

Nichols, D., Cahoon, N., Trakhtenberg, E. M., Pham, L., Mehta, A., Belanger, A., et al. (2010). Use of ichip for high-throughput in situ cultivation of "uncultivable" microbial species. Appl. Environ. Microbiol. 76, 2445-2450. doi: 10.1128/AEM.01754-09

Nübel, U., Garcia-Pichel, F., Kühl, M., and Muyzer, G. (1999). Quantifying microbial diversity: morphotypes, $16 \mathrm{~S}$ rRNA genes, and carotenoids of oxygenic phototrophs in microbial mats. Appl. Environ. Microbiol. 65, 422-430.
Ogura, A., Lin, M., Shigenobu, Y., Fujiwara, A., Ikeo, K., and Nagai, S. (2011). Effective gene collection from the metatranscriptome of marine microorganisms. BMC Genomics 12:S15. doi: 10.1186/1471-2164-12-S3-S15

Olano, C., Lombo, F., Mendez, C., and Salas, J. A. (2008). Improving production of bioactive secondary metabolites in actinomycetes by metabolic engineering. Metab. Eng. 10, 281-292. doi: 10.1016/j.ymben.2008.07.001

Pathom-Aree, W., Nogi, Y., Sutcliffe, I. C., Ward, A. C., Horikoshi, K., Bull, A. T., et al. (2006). Dermacoccus abyssi sp. nov., a piezotolerant actinomycete isolated from the Mariana Trench. Int. J. Syst. Evol. Microbiol. 56, 1233-1237. doi: 10.1099/ijs.0.64133-0

Pinhassi, J., Zweifel, U. L., and Hagstroëm, A. (1997). Dominant marine bacterioplankton species found among colony-forming bacteria. Appl. Environ. Microbiol. 63, 3359-3366.

Potts, B. C., and Lam, K. S. (2010). Generating a generation of proteasome inhibitors: from microbial fermentation to total synthesis of salinosporamide a (marizomib) and other salinosporamides. Mar. Drugs 8, 835-880. doi: $10.3390 / \mathrm{md} 8040835$

Pulido, D., and Jimenez, A. (1987). Optimization of gene expression in Streptomyces lividans by a transcription terminator. Nucleic Acids Res. 15, 4227-4240. doi: 10.1093/nar/15.10.4227

Purnick, P. E., and Weiss, R. (2009). The second wave of synthetic biology: from modules to systems. Nat. Rev. Mol. Cell Biol. 10, 410-422. doi: 10.1038/nrm2698

Rastogi, G., and Sani, R. (2011). "Molecular techniques to assess microbial community structure, function, and dynamics in the environment," in Microbes and Microbial Technology, eds I. Ahmad, F. Ahmad, and J. Pichtel (New York, NY: Springer), 29-57.

Reddy, L. R., Saravanan, P., and Corey, E. J. (2004). A simple stereocontrolled synthesis of salinosporamide A. J. Am. Chem. Soc. 126, 6230-6231. doi: $10.1021 /$ ja048613p

Richter, T. K., Hughes, C. C., and Moore, B. S. (2015). Sioxanthin, a novel glycosylated carotenoid, reveals an unusual subclustered biosynthetic pathway. Environ. Microbiol. 17, 2158-2171. doi: 10.1111/1462-2920.12669

Riedlinger, J., Reicke, A., Zähner, H., Krismer, B., Bull, A. T., Maldonado, L. A., et al. (2004). Abyssomicins, inhibitors of the para-aminobenzoic acid pathway produced by the marine Verrucosispora strain AB-18-032. J. Antibiot. 57, 271-279. doi: 10.7164/antibiotics.57.271

Sato, S., Iwata, F., Yamada, S., and Katayama, M. (2012). Neomaclafungins A-I: oligomycin-class macrolides from a marine-derived actinomycete. J. Nat. Prod. 75, 1974-1982. doi: 10.1021/np300719g

Schneemann, I., Ohlendorf, B., Zinecker, H., Nagel, K., Wiese, J., and Imhoff, J. F. (2010). Nocapyrones A-D, $\gamma$-pyrones from a Nocardiopsis strain isolated from the marine sponge Halichondria panicea. J. Nat. Prod. 73, 1444-1447. doi: $10.1021 / \mathrm{np} 100312 \mathrm{f}$

Schorn, M. A., Alanjary, M. M., Aguinaldo, K., Korobeynikov, A., Podell, S., Patin, N., et al. (2016). Sequencing rare marine actinomycete genomes reveals high density of unique natural product biosynthetic gene clusters. Microbiology 162, 2075-2086. doi: 10.1099/mic.0.000386

Schultz, A. W., Oh, D. C., Carney, J. R., Williamson, R. T., Udwary, D. W., Jensen, P. R., et al. (2008). Biosynthesis and structures of cyclomarins and cyclomarazines, prenylated cyclic peptides of marine actinobacterial origin. $J$. Am. Chem. Soc. 130, 4507-4516. doi: 10.1021/ja711188x

Schulze, C. J., Donia, M. S., Siqueira-Neto, J. L., Ray, D., Raskatov, J. A., Green, R. E., et al. (2015a). Genome-directed lead discovery: biosynthesis, structure elucidation, and biological evaluation of two families of polyene macrolactams against Trypanosoma brucei. ACS Chem. Biol. 10, 2373-2381. doi: $10.1021 /$ acschembio.5b00308

Schulze, C. J., Navarro, G., Ebert, D., DeRisi, J., and Linington, R. G. (2015b). Salinipostins A-K, long-chain bicyclic phosphotriesters as a potent and selective antimalarial chemotype. J. Org. Chem. 80, 1312-1320. doi: $10.1021 /$ jo5024409

Siegl, T., and Luzhetskyy, A. (2012). Actinomycetes genome engineering approaches. Antonie Van Leeuwenhoek 102, 503-516. doi: 10.1007/s10482-012-9795-y

Siegl, T., Tokovenko, B., Myronovskyi, M., and Luzhetskyy, A. (2013). Design, construction and characterisation of a synthetic promoter library for fine-tuned gene expression in actinomycetes. Metab. Eng. 19, 98-106. doi: 10.1016/j.ymben.2013.07.006 
Silver, L., and Bostian, K. (1990). Screening of natural products for antimicrobial agents. Eur. J. Clin. Microbiol. Infect. Dis. 9, 455-461. doi: 10.1007/BF01964283 Simmons, L., Kaufmann, K., Garcia, R., Schwär, G., Huch, V., and Müller, R. (2011). Bendigoles D-F, bioactive sterols from the marine spongederived Actinomadura sp. SBMs009. Bioorg. Med. Chem. 19, 6570-6575. doi: 10.1016/j.bmc.2011.05.044

Singh, S. B., Young, K., and Miesel, L. (2011). Screening strategies for discovery of antibacterial natural products. Expert Rev. Anti Infect. Ther. 9, 589-613. doi: $10.1586 /$ eri.11.81

Slattery, M., Ankisetty, S., Corrales, J., Marsh-Hunkin, K. E., Gochfeld, D. J., Willett, K. L., et al. (2012). Marine proteomics: a critical assessment of an emerging technology. J. Nat. Prod. 75, 1833-1877. doi: 10.1021/np300366a

Sousa, T. D. S., Jimenez, P. C., Ferreira, E. G., Silveira, E. R., Braz-Filho, R., Pessoa, O. D., et al. (2012). Anthracyclinones from Micromonospora sp. J. Nat. Prod. 75, 489-493. doi: 10.1021/np200795p

Stewart, E. J. (2012). Growing unculturable bacteria. J. Bacteriol. 194, 4151-4160. doi: 10.1128/JB.00345-12

Subramani, R., and Aalbersberg, W. (2013). Culturable rare Actinomycetes: diversity, isolation and marine natural product discovery. Appl. Microbiol. Biotechnol. 97, 9291-9321. doi: 10.1007/s00253-013-5229-7

Sun, H., Liu, Z., Zhao, H., and Ang, E. L. (2015). Recent advances in combinatorial biosynthesis for drug discovery. Drug Des. Devel. Ther. 9, 823-833. doi: 10.2147/DDDT.S63023

Takagi, M., Motohashi, K., Khan, S. T., Hashimoto, J., and Shin-ya, K. (2010). JBIR-65, a new diterpene, isolated from a sponge-derived Actinomadura sp. SpB081030SC-15. J. Antibiot. 63, 401-403. doi: 10.1038/ja.2010.61

Tang, X., Li, J., Millán-Aguinaaga, N., Zhang, J. J., O’Neill, E. C., Ugalde, J. A., et al. (2015). Identification of thiotetronic acid antibiotic biosynthetic pathways by target-directed genome mining. ACS Chem. Biol. 10, 2841-2849. doi: 10.1021 /acschembio. 5 b00658

Tiwari, K., and Gupta, R. K. (2013). Diversity and isolation of rare actinomycetes: an overview. Crit. Rev. Biotechnol. 39, 256-294. doi: 10.3109/1040841x.2012.709819

Tong, Y., Charusanti, P., Zhang, L., Weber, T., and Lee, S. Y. (2015). CRISPR-Cas9 based engineering of actinomycetal genomes. ACS Synth. Biol. 4, 1020-1029. doi: 10.1021/acssynbio. 5 b00038

Trindade, M., van Zyl, L. J., Navarro-Fernández, J., and Abd Elrazak, A. (2015). Targeted metagenomics as a tool to tap into marine natural product diversity for the discovery and production of drug candidates. Front. Microbiol. 6:890. doi: $10.3389 /$ fmicb.2015.00890

Udwary, D. W., Zeigler, L., Asolkar, R. N., Singan, V., Lapidus, A., Fenical, W., et al. (2007). Genome sequencing reveals complex secondary metabolome in the marine actinomycete Salinispora tropica. Proc. Natl. Acad. Sci. U.S.A. 104, 10376-10381. doi: 10.1073/pnas.0700962104

Vartoukian, S. R., Palmer, R. M., and Wade, W. G. (2010). Strategies for culture of 'unculturable' bacteria. FEMS Microbiol. Lett. 2010, 1-7. doi: 10.1111/j.1574-6968.2010.02000.x

Wang, H., Yang, L., Wu, K., and Li, G. (2014). Rational selection and engineering of exogenous principal sigma factor ( $\sigma \mathrm{HrdB})$ to increase teicoplanin production in an industrial strain of Actinoplanes teichomyceticus. Microb. Cell Fact. 13:10. doi: 10.1186/1475-2859-13-10

Wang, W., Li, X., Wang, J., Xiang, S., Feng, X., and Yang, K. (2013). An engineered strong promoter for streptomycetes. Appl. Environ. Microbiol. 79, 4484-4492. doi: 10.1128/AEM.00985-13

Weber, T., and Kim, H. U. (2016). The secondary metabolite bioinformatics portal: Computational tools to facilitate synthetic biology of secondary metabolite production. Synth. Syst. Biotechnol. 1, 69-79. doi: 10.1016/j.synbio.2015.12.002

Webster, N. S., Taylor, M. W., Behnam, F., Lücker, S., and Rattei, T., Whalan, S. et al. (2010). Deep sequencing reveals exceptional diversity and modes of transmission for bacterial sponge symbionts. Environ. Microbiol. 12, 2070-2082. doi: 10.1111/j.1462-2920.2009.02065.x

Weissman, K. J. (2007). Mutasynthesis-uniting chemistry and genetics for drug discovery. Trends Biotechnol. 25, 139-142. doi: 10.1016/j.tibtech.2007.02.004

Wenzel, S. C., and Müller, R. (2005). Recent developments towards the heterologous expression of complex bacterial natural product biosynthetic pathways. Curr. Opin. Biotechnol. 16, 594-606. doi: 10.1016/j.copbio.2005.10.001
Williams, P. G., Asolkar, R. N., Kondratyuk, T., Pezzuto, J. M., Jensen, P. R., and Fenical, W. (2007a). Saliniketals, A., and B, bicyclic polyketides from the marine actinomycete Salinispora arenicola. J. Nat. Prod. 70, 83-88. doi: $10.1021 / \mathrm{np} 0604580$

Williams, P. G., Buchanan, G. O., Feling, R. H., Kauffman, C. A., Jensen, P. R., and Fenical, W. (2005). New cytotoxic Salinosporamides from the marine actinomycete Salinispora tropica. J. Org. Chem. 70, 6196-6203. doi: 10.1021/jo050511+

Williams, P. G., Miller, E. D., Asolkar, R. N., Jensen, P. R., and Fenical, W. (2007b). Arenicolides, A. C., 26-membered ring macrolides from the marine actinomycete Salinispora arenicola. J. Org. Chem. 72, 5025-5034. doi: $10.1021 /$ jo061878x

Winn, M., Fyans, J. K., Zhuo, Y., and Micklefield, J. (2016). Recent advances in engineering nonribosomal peptide assembly lines. Nat. Prod. Rep. 33, 317-347. doi: $10.1039 / \mathrm{C} 5 \mathrm{NP} 00099 \mathrm{H}$

Wu, J., Gao, W., Johnson, R. H., Zhang, W., and Meldrum, D. R. (2013). Integrated metagenomic and metatranscriptomic analyses of microbial communities in the meso-and bathypelagic realm of North Pacific Ocean. Mar. Drugs 11, 3777-3801. doi: 10.3390/md11103777

Wu, Z. C., Li, S., Nam, S. J., Liu, Z., and Zhang, C. (2013). Nocardiamides, A., and $\mathrm{B}$, two cyclohexapeptides from the marine-derived actinomycete Nocardiopsis sp. CNX037. J. Nat. Prod. 76, 694-701. doi: 10.1021/np400009a

Wyche, T. P., Hou, Y., Braun, D., Cohen, H. C., Xiong, M. P., and Bugni, T. S. (2011). First natural analogs of the cytotoxic thiodepsipeptide thiocoraline A from a marine Verrucosispora sp. J. Org. Chem. 76, 6542-6547. doi: $10.1021 /$ jo200661n

Wyche, T. P., Hou, Y., Vazquez-Rivera, E., Braun, D., and Bugni, T. S. (2012). Peptidolipins B-F, antibacterial lipopeptides from an ascidian-derived Nocardia sp. J. Nat. Prod. 75, 735-740. doi: 10.1021/np300016r

Wyche, T. P., Piotrowski, J. S., Hou, Y., Braun, D., Deshpande, R., McIlwain, S., et al. (2014). Forazoline A: marine-derived polyketide with antifungal in vivo Efficacy. Angew. Chem. Int. Ed. 126, 11767-11770. doi: 10.1002/ange.201405990

Wyche, T. P., Standiford, M., Hou, Y., Braun, D., Johnson, D. A., Johnson, J. A., et al. (2013). Activation of the nuclear factor E2-related factor 2 pathway by novel natural products halomadurones A-D and a synthetic analogue. Mar. Drugs 11, 5089-5099. doi: 10.3390/md11125089

Yamanaka, K., Reynolds, K. A., Kersten, R. D., Ryan, K. S., Gonzalez, D. J., Nizet, V., et al. (2014). Direct cloning and refactoring of a silent lipopeptide biosynthetic gene cluster yields the antibiotic taromycin A. Proc. Natl. Acad. Sci. U.S.A. 111, 1957-1962. doi: 10.1073/pnas.1319584111

Yang, C., Huang, C., Zhang, W., Zhu, Y., and Zhang, C. (2015). Heterologous expression of fluostatin gene cluster leads to a bioactive heterodimer. Org. Lett. 17, 5324-5327. doi: 10.1021/acs.orglett.5b02683

Yeung, K. S., and Paterson, I. (2005). Advances in the total synthesis of biologically important marine macrolides. Chem. Rev. 105, 4237-4313. doi: $10.1021 / \mathrm{cr} 040614 \mathrm{c}$

Young, I. S., and Baran, P. S. (2009). Protecting-group-free synthesis as an opportunity for invention. Nat. Chem. 1, 193-205. doi: 10.1038/nchem.216

Zeng, Y., Zou, Y., Grebmeier, J., He, J., and Zheng, T. (2012). Cultureindependent and -dependent methods to investigate the diversity of planktonic bacteria in the northern Bering Sea. Polar Biol. 35, 117-129. doi: 10.1007/s00300-011-1044-8

Zengler, K., and Palsson, B. O. (2012). A road map for the development of community systems (CoSy) biology. Nat. Rev. Microbiol. 10, 366-372. doi: $10.1038 /$ nrmicro2763

Zengler, K., Toledo, G., Rappé, M., Elkins, J., Mathur, E. J., Short, J. M., et al. (2002). Cultivating the uncultured. Proc. Natl. Acad. Sci. U.S.A. 99, 15681-15686. doi: 10.1073/pnas.252630999

Zhang, W., Liu, Z., Li, S., Lu, Y., Chen, Y., Zhang, H., et al. (2012). Fluostatins IK from the South China Sea-derived Micromonospora rosaria SCSIO N160. J. Nat. Prod. 75, 1937-1943. doi: 10.1021/np300505y

Zhou, X., Huang, H., Chen, Y., Tan, J., Song, Y., Zou, J., et al. (2012). Marthiapeptide, A., an anti-infective and cytotoxic polythiazole cyclopeptide from a $60 \mathrm{~L}$ scale fermentation of the deep sea-derived Marinactinospora thermotolerans SCSIO 00652. J. Nat. Prod. 75, 2251-2255. doi: 10.1021/np300554f 
Ziemert, N., Alanjary, M., and Weber, T. (2016). The evolution of genome mining in microbes-a review. Nat. Prod. Rep. 33, 988-1005. doi: 10.1039/c6np0 $0025 \mathrm{~h}$

Ziemert, N., Lechner, A., Wietz, M., Millán-Aguiñaga, N., Chavarria, K. L., and Jensen, P. R. (2014). Diversity and evolution of secondary metabolism in the marine actinomycete genus Salinispora. Proc. Natl. Acad. Sci. U.S.A. 111, E1130-E1139. doi: 10.1073/pnas.1324161111

Zotchev, S. B. (2012). Marine actinomycetes as an emerging resource for the drug development pipelines. J. Biotechnol. 158, 68-175. doi: $10.1016 /$ j.jbiotec.2011.06.002
Conflict of Interest Statement: The authors declare that the research was conducted in the absence of any commercial or financial relationships that could be construed as a potential conflict of interest.

Copyright (ㄷ 2017 Dhakal, Pokhrel, Shrestha and Sohng. This is an open-access article distributed under the terms of the Creative Commons Attribution License (CC $B Y)$. The use, distribution or reproduction in other forums is permitted, provided the original author(s) or licensor are credited and that the original publication in this journal is cited, in accordance with accepted academic practice. No use, distribution or reproduction is permitted which does not comply with these terms. 